\title{
Epidemiology of osteoarthritis: Zoetermeer survey. Comparison of radiological osteoarthritis in a Dutch population with that in 10 other populations
}

\author{
JAN L C M VAN SAASE, ${ }^{13}$ LEO K J VAN ROMUNDE, ${ }^{1}$ ARNOLD CATS ${ }^{2}$ \\ JAN P VANDENBROUCKE, ${ }^{3}$ AND HANS A VALKENBURG
}

From the ${ }^{1}$ Department of Epidemiology, Erasmus University Medical School, Rotterdam, The Netherlands; and the Departments of ${ }^{2}$ Rheumatology and ${ }^{3}$ Clinical Epidemiology, Leiden State University, Leiden, The Netherlands

SUMMARY The prevalence of mild and severe radiological osteoarthritis was investigated in a random sample of 6585 inhabitants of a Dutch village. Radiographs were graded 0-4 according to the criteria described by Kellgren and Lawrence. The prevalence of radiological osteoarthritis increased strongly with age and was highest for cervical spine (peak: men $84 \cdot 8 \%$, women $84 \cdot 3 \%$ ), lumbar spine (peak: $71.9 \%$, women $67 \cdot 3 \%$ ), and distal interphalangeal joints of the hands (peak: men $64.4 \%$, women $76 \%$ ). Prevalence did not exceed $10 \%$ in sacroiliac joints, lateral carpometacarpal joints, and tarsometatarsal joints. Severe radiological osteoarthritis (grade 3 or grade 4) was uncommon under age 45; in elderly persons the prevalence of severe radiological osteoarthritis did not exceed $20 \%$ except for the cervical and lumbar spine, distal interphalangeal joints of the hands and, in women only, metacarpophalangeal joints, first carpometacarpal joints, first metatarsophalangeal joints, and knees. Overall, differences between men and women were small except for hips and knees; however, severe radiological osteoarthritis was found in a higher proportion in most of the joints in women. Our data were compared with data from similar population surveys. The slope between joint involvement and age was strikingly constant for most of the joints. Differences between populations were mainly differences in level. These differences of prevalence of radiological osteoarthritis may be attributed to interobserver differences-that is, different criteria used to establish radiological osteoarthritis, in addition to genetic or environmental factors, or both.

Key words: prevalence, human.

Osteoarthritis causes morbidity that will be of increasing importance in populations with greater proportions of elderly people. Epidemiology can help establish the causes of chronic diseases like osteoarthritis. ${ }^{1}$ One of the major tools used by epidemiologists to accomplish this is a comparison of populations. Epidemiological studies have shown that radiological osteoarthritis is a ubiquitous disorder. Although present in some individuals around

Accepted for publication 4 August 1988.

Correspondence to Dr Jan L C M van Saase, Department of Clinical Epidemiology, Leiden State University, PO Box 9600, 2300 RC Leiden, The Netherlands. age 25, osteoarthritis mainly affects older age groups. ${ }^{3}$ Several investigations compared the prevalence of osteoarthritis in different races, different populations, and different geographic areas. Although a number of carefully conducted large population surveys are available, only a limited number of these were adequately compared. ${ }^{4-7}$ In this paper we describe the prevalence of radiological osteoarthritis of 22 joints and groups of joints in a random population sample of 6585 inhabitants of Zoetermeer in the Netherlands. The results are compared with results from 10 similar population surveys. 


\section{Subjects and methods}

\section{ZOETERMEER POPULATION}

To study the prevalence and determinants of rheumatic and cardiovascular diseases a population survey was conducted between 1975 and 1978 in two districts of Zoetermeer, a suburban metropolitan area near The Hague in The Netherlands. ${ }^{8}$ Respondents were inhabitants of the original agricultural village and the recently built parts, which were principally inhabited by white collar workers. All inhabitants of the old village centre and one part of the new area were invited to participate in this survey. Of 4134 eligible men and 4523 eligible women of 19 years and older, $6585(76 \cdot 1 \%)$ participated in the study (3109 men, 3476 women). Survey completion was greatest between 20 and 64 years of age $(78.2 \%)$ and was only $61 \%$ in those over 65 . Information was gathered on previous medical history, rheumatic complaints, profession, daily activities, drug use, schooling history, and lifestyle habits by a questionnaire. In a specially equippedos? centre joints were investigated, blood pressure, $\overline{0}$ weight, and height were measured, and radiographs흠 were taken of all 6585 participants. Blood was $\frac{\bar{c}}{\triangle}$ obtained for determination of rheumatoid factor,, $\mathbb{D}$ total serum cholesterol, and uric acid.

\section{RA D I O G R A P H S}

Radiographs were obtained of hands, forefeet, and $\overrightarrow{\vec{\omega}}$ lateral cervical spine. Several additional radiographs $\odot$ were taken of all respondents of 45 years and older: lumbar spine in anteflexion and dorsiflexion and pelvis and knees in anteroposterior and standing ${ }_{A}^{\infty}$ position. During the last year of the survey radio-i graphs of both shoulders were taken of all respon- $\rightarrow$ dents of 45 years and older. Examination of radio-o graphs was performed by two investigators indepen--
ZOETERMEER POPULATION (EPOZ)

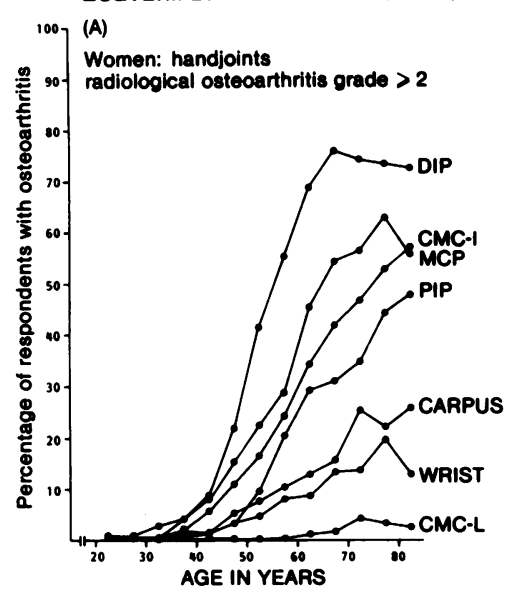

ZOETERMEER POPULATION (EPOZ)

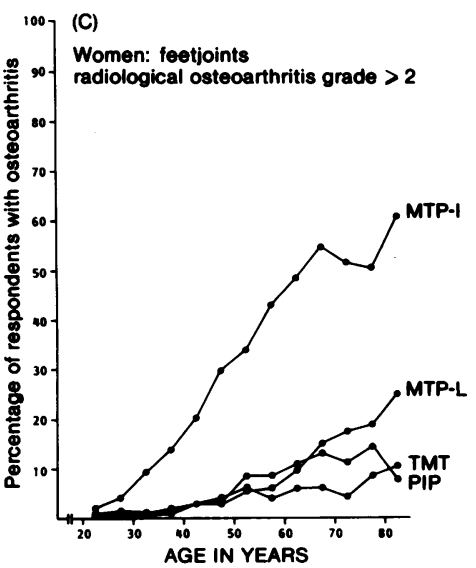

ZOETERMEER POPULATION (EPOZ)

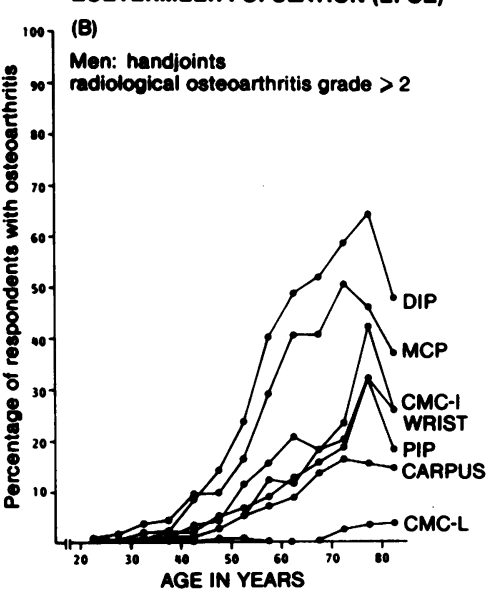

ZOETERMEER POPULATION (EPOZ)

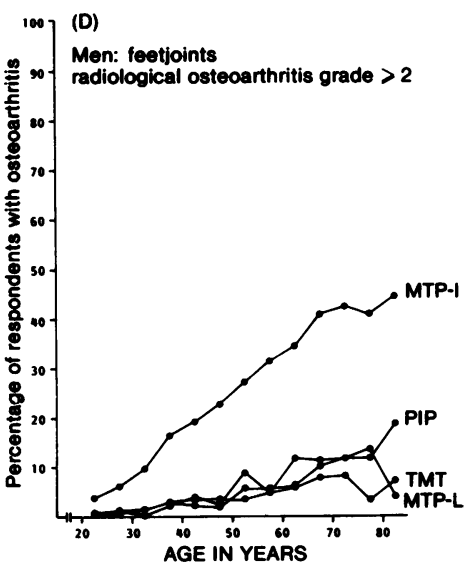

Fig. 1 Age specific prevalences of osteoarthritis of hands and feet for inhabitants of Zoetermeer. $D I P=$ distal interphalangeal joints, CMC-I=first carpometacarpal joint; $M C P=$ metacarpophalangea? joints; $P I P=$ proximal interphalangeal joints; $C M C-L=$ second to fifth carpometacarpal joints; $M T P-I=$ first metatarsophalangea joint; $M T P-L=$ second to fifth metatarsophalangeal joints; $T M T=$ tarsometatarsal joints. 
dently, based on the grading system for radiological osteoarthritis according to the Atlas of Standard Radiographs of arthritis. ${ }^{9}$ This atlas contains radiographic examples of osteoarthritis of several joints in several stages of the disease. A five point scale has been used for staging $(0=$ absent, $1=$ dubious, $2=$ mild, $3=$ moderate, $4=$ severe). Small joints of hands and feet were graded as groups (Figs 1 and 2) according to the most affected joint of the whole group. Right and left side were not separated, except for hips, knees, shoulders, and sacroiliac joints. When a one point difference in grading occurred between both investigators the higher score was accepted, but where there was greater disagreement about the grading or when one observer scored grade 1 and the other grade 2 the films were reassessed at a joint reading session until a final score was agreed. Interobserver and intraobserver agreement has been discussed elsewhere. ${ }^{10}$
CRITERIA FOR CHOICE OF COMPARISON POPULATIONS

Population surveys suited for comparison were cross sectional and contained random or stratified population samples. Not all surveys could be used: radiographs had to be available of nearly all respondents without regard to complaints; an acceptable sample size of above 500 participants was necessary; sex and age specific information about radiological osteoarthritis had to be available; and the radiological osteoarthritis data had to be presented for individual joints or groups of joints. Furthermore, information about the origin of the population, the sample size, the sampling technique, and the range of age and of joints for which radiographs had been taken had to be available. Table 1 presents the basic data of 10 populations with a total of 22629 participants. Two large surveys, the Alaskan Eskimo ${ }^{11}$ and the Jamaican survey, ${ }^{12}$ were not included because no

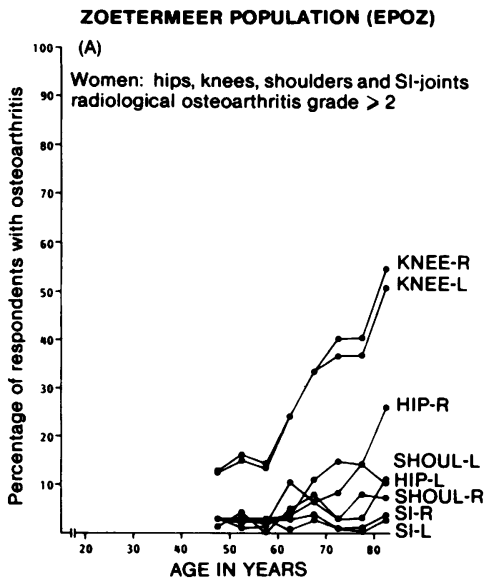

ZOETERMEER POPULATION (EPOZ)

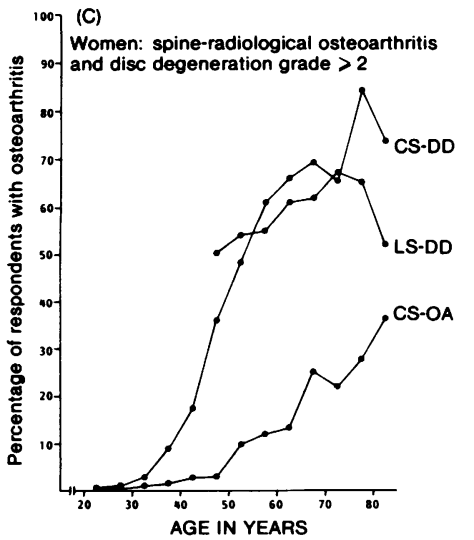

ZOETERMEER POPULATION (EPOZ)

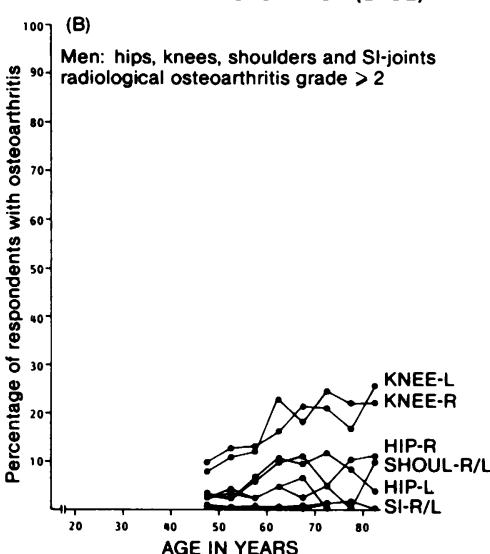

ZOETERMEER POPULATION (EPOZ)

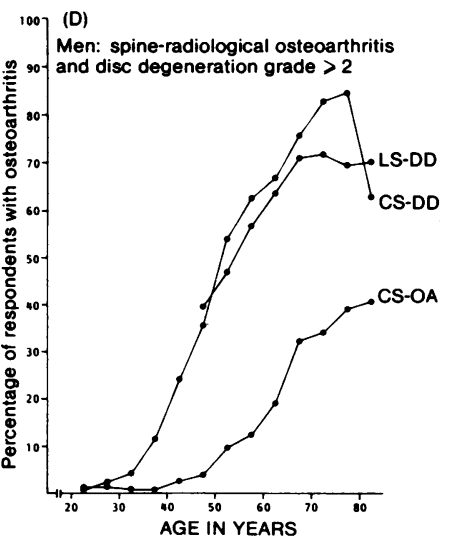

Fig. 2 Age specific prevalences of osteoarthritis of large joints and disc degeneration for inhabitants of Zoetermeer. $L=$ left; $R=$ right; $S H O U L=$ shoulder SI=sacroiliac joints; $C S-D D=$ cervical spine disc degeneration; $L S-D D=$ lumbar spine disc degeneration; $C S-O A=$ cervical spine osteoarthritis. 
Table 1 Radiological osteoarthritis data from 10 population surveys

\begin{tabular}{|c|c|c|c|c|}
\hline $\begin{array}{l}\text { Population } \\
\text { (reference) }\end{array}$ & Age & Radiographs* & $\begin{array}{l}\text { Sample } \\
\text { size }\end{array}$ & Method \\
\hline $\begin{array}{l}\text { Leigh } \\
\qquad(3,13) 1954 \text { England }\end{array}$ & $55-64$ & $\mathrm{~h}, \mathrm{f}, \mathrm{c}, \mathrm{l}, \mathrm{p}(35+)$ & 1343 & $\begin{array}{l}\text { Stratified } \\
\quad \text { sample } 200 / \text { decade }\end{array}$ \\
\hline $\begin{array}{l}\text { Wensleydale } \\
\quad(3,13) 1958 \text { England }\end{array}$ & $15+$ & $\begin{array}{l}\mathrm{h}, \mathrm{f}, \mathrm{c}, 1(35+) \\
\mathrm{p}(35+)\end{array}$ & 891 & $\begin{array}{l}\text { Village (urban } \\
\text { and rural) }\end{array}$ \\
\hline $\begin{array}{l}\text { Blackfeet Indians } \\
\text { (14) } 1961 \text { USA }\end{array}$ & $30+$ & $h, f, c, p(45+)$ & 1101 & Tribe \\
\hline $\begin{array}{l}\text { Pima Indians } \\
\text { (14) } 1965 \text { USA }\end{array}$ & $30+$ & $\mathrm{h}, \mathrm{f}, \mathrm{c}, \mathrm{p}(45+)$ & 969 & Tribe \\
\hline $\begin{array}{l}\text { Tecumseh } \\
\text { (15) } 1962 \text { USA }\end{array}$ & $35+$ & h,c & 4415 & $\begin{array}{l}\text { Age and social class } \\
\text { strata }\end{array}$ \\
\hline $\begin{array}{l}\text { Sofia } \\
\text { (16) } 1964 \text { Bulgaria }\end{array}$ & $15+$ & $h, f, c, l, p$ & 4318 & $\begin{array}{l}\text { Age stratified } \\
\text { random sample }\end{array}$ \\
\hline $\begin{array}{l}\text { Tswana } \\
\text { (6) } 1970 \text { South Africa }\end{array}$ & $30+$ & $\begin{array}{c}\text { h,f,p }(55+), \\
l(55+)\end{array}$ & 801 & Village \\
\hline $\begin{array}{l}\text { HANES I } \\
\quad(17,18) \text { 1971-1974 USA }\end{array}$ & $25+$ & $\mathrm{k}, \mathrm{p}$ & 6913 & Representative sample \\
\hline $\begin{array}{l}\text { Iwata Kamitonda } \\
\text { (personal communication) } \\
\text { 1972 Japan }\end{array}$ & $30+$ & $h, f, p$ & 1335 & Village \\
\hline $\begin{array}{l}\text { Tsikundamalema } \\
\text { (7) } 1984 \text { South Africa }\end{array}$ & $18+$ & $h, f$ & 543 & Village \\
\hline
\end{tabular}

age and sex specific prevalences were presented for individual joints.

Japanese population data from Kamitonda ( $\mathrm{K}$ Shichikawa, personal communication) were included despite the lack of radiological information in $45 \%$ because no other acceptable population survey data were available about Asian people. The Sofia data are the only ones from Eastern Europe, but they were presented while the survey was not fully completed and it is uncertain whether this was reason for bias. The Atlas of Standard Radiographs was used in all surveys except the Tecumseh study. ${ }^{15}$ Most radiographs were interpreted by investigators originally trained by J S Lawrence or J H Kellgren.

\section{Results}

Sex and age specific prevalences of radiological osteoarthritis of 22 joints and joint groups of the Zoetermeer population are presented as graphs (Figs 1 and 2). Age specific prevalences for both mild and severe osteoarthritis, which we obtained in this survey, are given in full in Tables 2 and 3 . Kellgren's grades 0 and 1 were considered as absence and grade 2, 3, and 4 as presence of radiological osteoarthritis. Shoulders were included in the graphs, though radiographs were taken in only one third of the total population sample and only few subjects in the higher age categories were present. The standard errors of the prevalence of these joints will therefore be larger.
Increased radiological osteoarthritis is strongly related to aging. This holds both for small joints and for large weight bearing joints and for both men and women. Small joints of the hands, tarsometatarsal, and lateral metatarsophalangeal joints of the feet $\stackrel{\odot}{\varrho}$ and both knees were more often involved in women $\overrightarrow{0}$ of all ages. The hips were more often involved in 3 middle aged men and the lumbar and cervical spine were more often involved in all men. There was no: significant sex difference except for knees, hips in those aged 65 and over, and distal interphalangealo joints of the hands.

Considerable differences were found for the age of onset and the prevalence of radiological osteoarthritis with age of different joints. Distal interphalangeal and metacarpophalangeal joints were음 already affected in $10 \%$ and first metatarsopha- $\rightarrow$ langeal joints even in $20 \%$ of the normal population? at the age of 40 . Disc degeneration of lumbar and $N$ cervical spine was more often present than absent in both men and women above the age of 50 .

To compare differences and similarities of prevalences of radiological osteoarthritis between the populations studied so far graphs were used in whicho the percentages of involved joints were plotted against age. Not all joints about which data were? available are presented here. Very different joints $\underline{T}$ are given as examples (Figs 3 and 4). Standard웅 errors are not indicated on the graphs because they were not always available and because of the density of the lines. During assessment of the graphs it musto be remembered that sample sizes were sometimes 


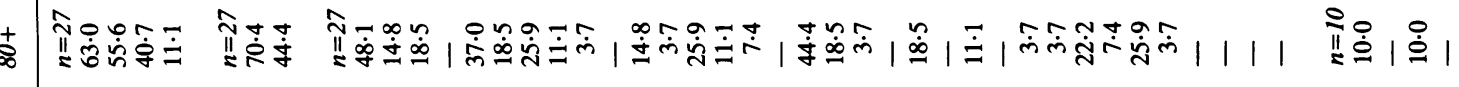

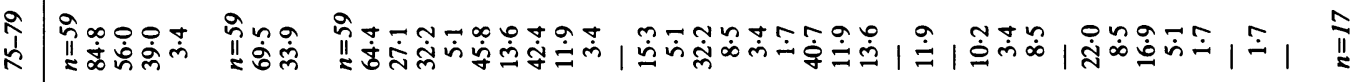

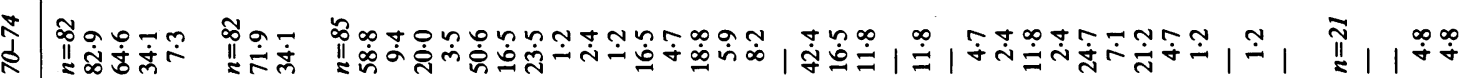

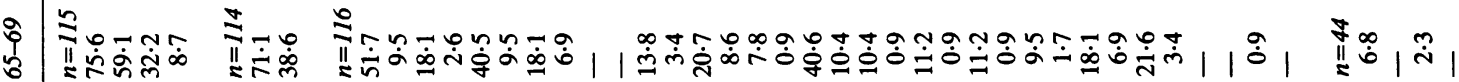

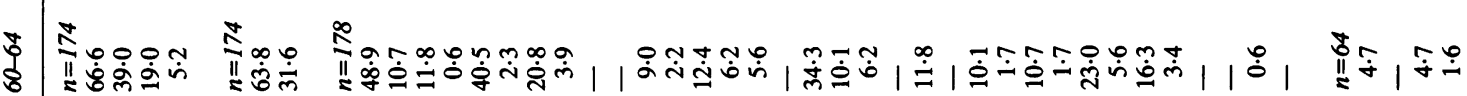
|⿱宀八

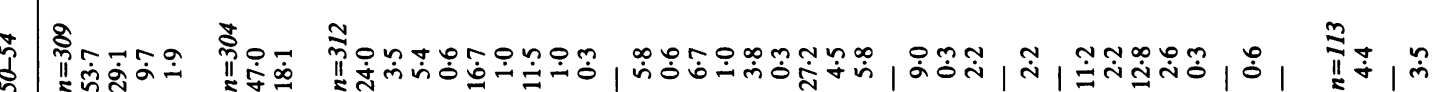

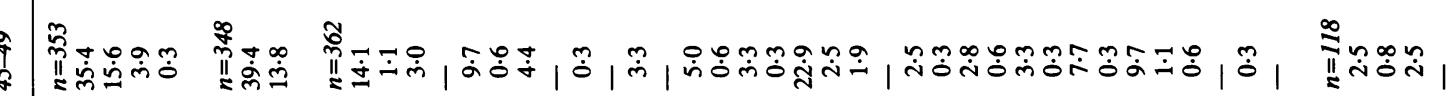

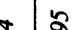
\$

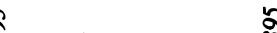

II $\dot{\vec{j}} \dot{\dot{\omega}}$

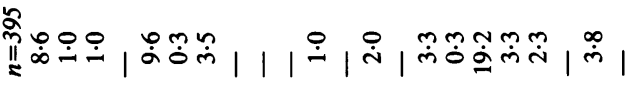

के

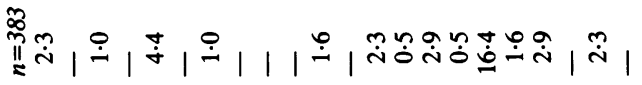

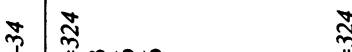

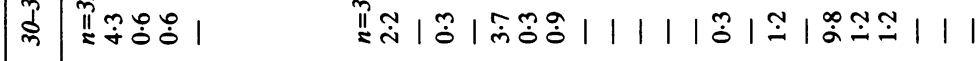
$\infty$

II ฉิน

\&

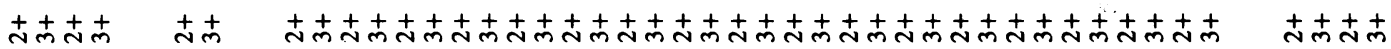




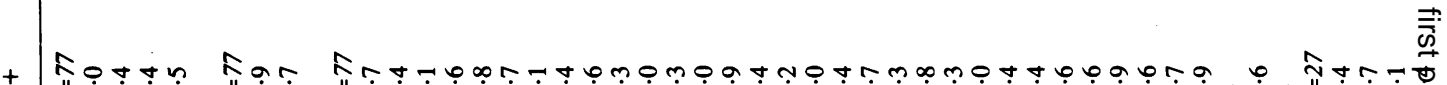

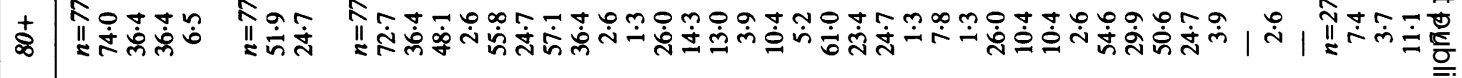

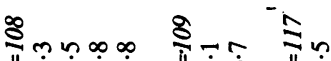

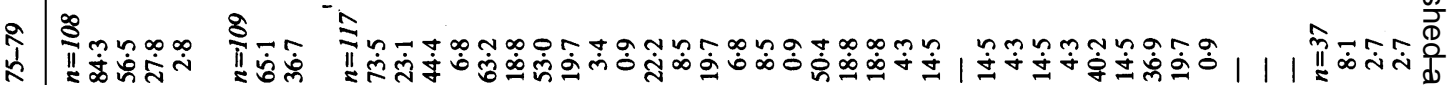

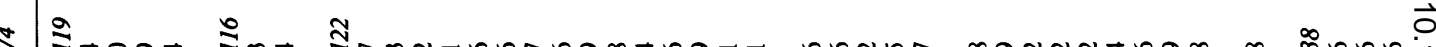

ई II

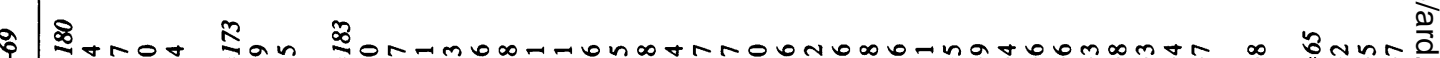

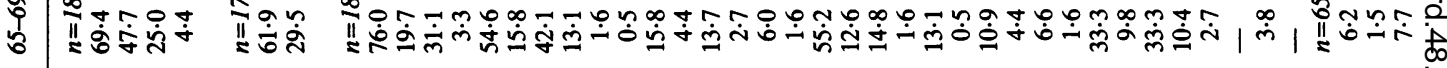

\إ

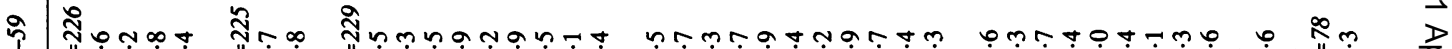

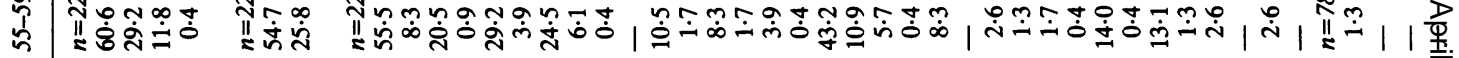

E

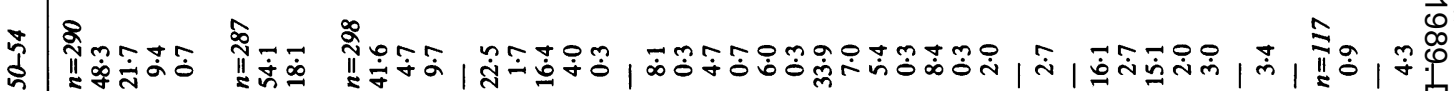

|

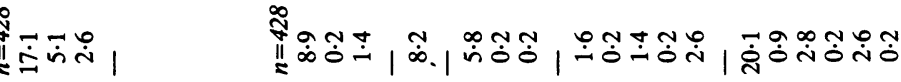

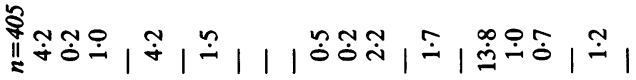

色

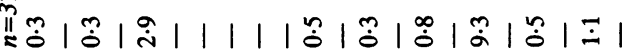

$\approx$

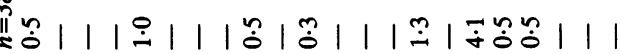

亏ิ

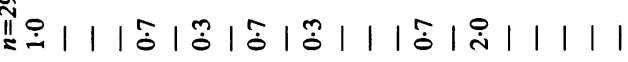

$\stackrel{+}{\sim}+\stackrel{+}{n} \stackrel{+}{\sim} \stackrel{+}{m}$

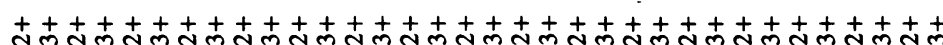

$+++\Phi$ 
(A)
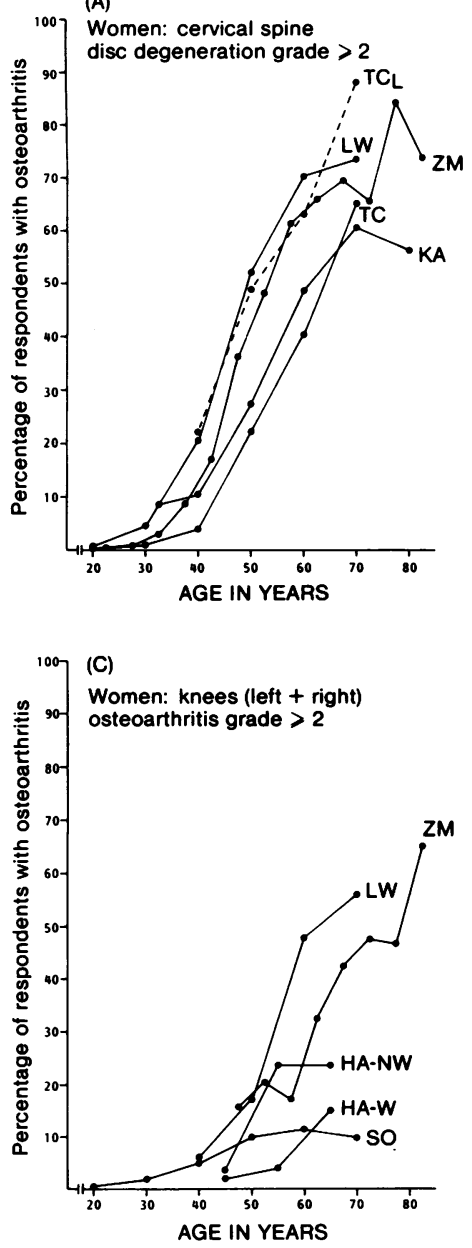

(B)

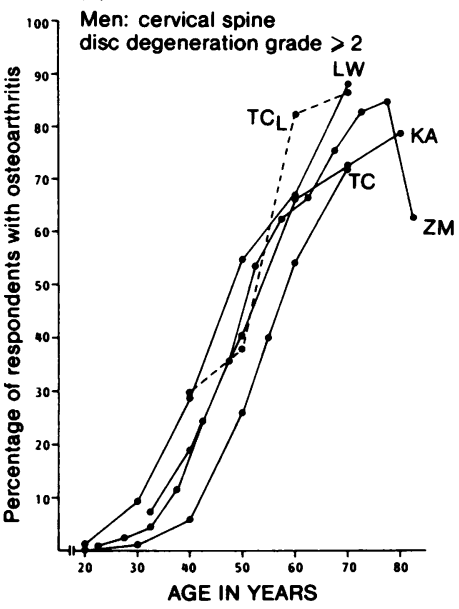

Fig. 3 Age specific prevalences of cervical spine disc degeneration and osteoarthritis of the knees in different populations. $L W=$ Leigh and Wensleydale; $Z M=$ Zoetermeer; $T C=$ Tecumseh; $K A=$ Kamitonda;

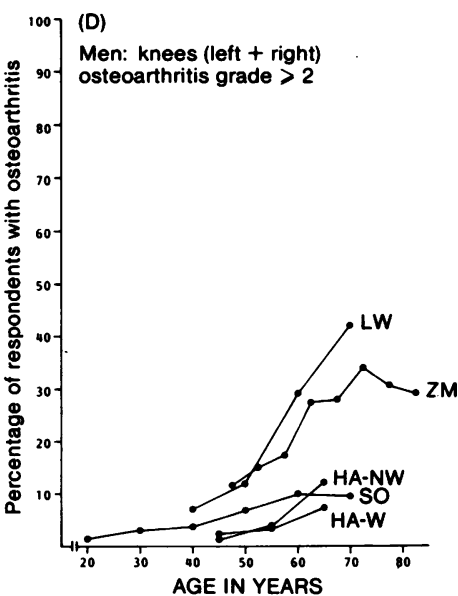
$H A=H A N E S ; S O=$ Sofia . small (Table 1). The highest age category almost always contained few participants and was certainly not always an adequate sample of the population.

The graphs show, firstly, that there are differences in level between populations and, secondly, that the slope of most lines is very much the same for individual joints and groups of joints in the various populations. Notable exceptions are Blackfeet and Pima indians, who have a very high prevalence of radiological osteoarthritis of the distal interphalangeal joints, Bulgarians, who show a very low prevalence of radiological osteoarthritis of the distal interphalangeal joints, and Tswana and Tsikundamalema women, who have a very low carpometacar- pal joint involvement. We are not certain whether the carpometacarpal joints were separated into lateral and first carpometacarpal (base of thumb) joints. Data from Zoetermeer and Kamitonda concern the first carpometacarpal joint. Furthermore, it is remarkable that participants from the village of Tsikundamalema have a relatively high prevalence of radiological osteoarthritis of the distal interphalangeal joints and a low prevalence of the carpometacarpal joints. Other joints showed similar patterns: the same slope for the same joint, with differences in level and occasional exceptions. None of the populations had a low or high prevalence for all joints investigated. 

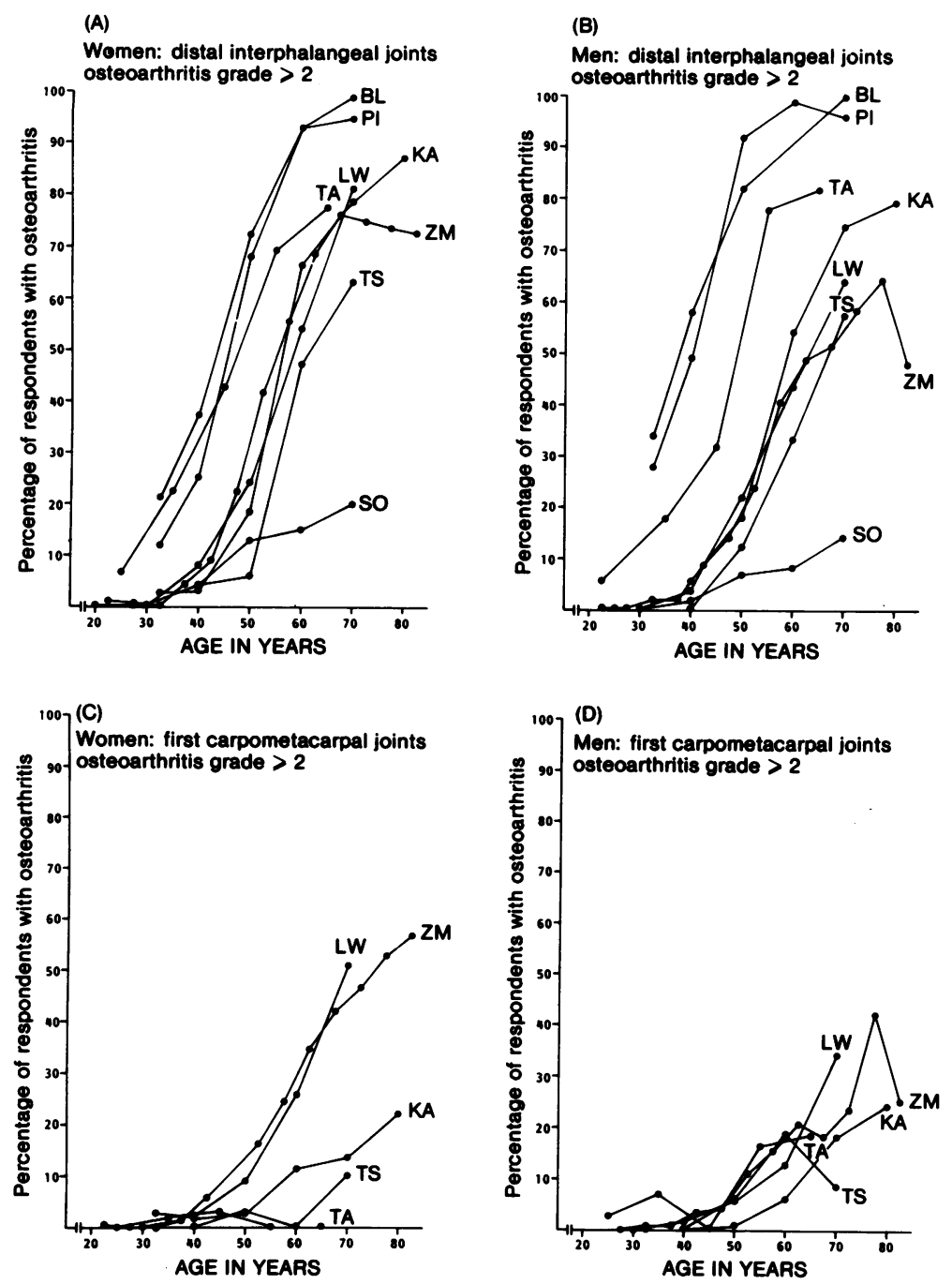

Fig. 4 Age specific prevalences of distal interphalangeal joints and carpometacarpal joints in different populations. $B L=$ Blackfeet Indians; $P$ I = Pima Indians; $K A=$ Kamitonda $; L=$ Leigh and Wensleydale;

$Z M=$ Zoetermeer $; T S=T$ swana; $T A=$ Tsikundamalema; $S O=$ Sofia

\section{Discussion}

The Zoetermeer population survey confirms the high prevalence of radiological osteoarthritis. The disorder increases progressively with age. Mild radiological osteoarthritis is more prevalent in women and severe radiological osteoarthritis is much more prevalent in women. From postmortem studies it is known that the pathological process takes place several years before radiological detection of the disorder is possible ${ }^{19}$ so the prevalence of radiological osteoarthritis by age as presented here is an underestimation of the actual prevalence of cartilage degeneration.
The prevalence of radiological osteoarthritis de creased slightly in very old people for a number of joints. This might be attributed to response bias. IR was reported recently, however, that women witkw $x$ ray changes of the knee were at increased risk for subsequent mortality. ${ }^{20}$ Obesity, ${ }^{182122}$ hypero tension, ${ }^{23}$ and diabetes mellitus, ${ }^{24}$ all associated with both osteoarthritis and a lower average life expectancy, may be responsible for this observation 0 Excess radiological osteoarthritis of the right hip? was found after the age of 75 , though it must be? remembered that sample sizes were small and this difference in prevalence could be due to a single anomalous result. 
All data were obtained from cross sectional population surveys and were therefore less suited for evaluation of the process of joint involvement by age. Conclusions about joint involvement and age can therefore only be drawn from these data if birth cohort effects are negligible. This may be a source of bias, for example, for populations where selective mortality occurred during periods of starvation or war. As no follow up surveys are available, however, we ignored possible birth cohort effects and compared the results of the Zoetermeer survey with those of 10 other population surveys. Figures 2A and 2B demonstrate identical slopes (parallelism) together with differences in level for most joints. This means that when the process of osteoarthritis first occurs in a certain joint or group of joints the rate of increase of degeneration of that joint or group of joints per unit of time is the same in all populations from that point on. A higher level means that the radiological appearance of osteoarthritis occurs at younger ages. Differences in level showed a tendency to increase while differences of slope remained minimal when several joints were considered together, as shown for all the joints of the hand. ${ }^{4}$

Differences between populations can be explained in several ways. Firstly, different investigators may be more or less inclined to give a higher or lower score, and interobserver variation is probable in the interpretation of radiographs. Furthermore, the freedom of interpretation of the standardising atlas is rather large. Interobserver variation as the sole cause for differences in level is less probable. Lawrence and Sebo read radiographs from 17 surveys with a total of 7919 participants. ${ }^{5}$ They found important differences between populations, though it was not stated whether these were differences in level or differences of slope. Secondly, it is quite possible that differences between populations are not artificial. Evidence from genetic as well as environmental studies indicates that differences are, at least in part, true differences. An increased or decreased presence of risk factors or protective factors may be responsible for these differences in level. Osteoporosis for instance seems to protect against osteoarthritis. ${ }^{25}$ Factors that influence (subchondral) bone density, like vitamin $\mathrm{D}$, alcohol consumption, and anthropometric status, differ between races and populations. ${ }^{26-28}$ Furthermore, differences in level may in part be explained by a different distribution of these risk factors. Obesity is a strong risk factor for osteoarthritis for a number of joints. ${ }^{82}$ Between populations with a high and a low percentage of obese persons a level difference is likely. If this obesity-osteoarthritis relation were not linear a difference of slope would exist.
Another explanation for differences in level is the distinction, as proposed by the American Rheumatism Association, ${ }^{29}$ between idiopathic and secondary types of osteoarthritis. This distinction was not reported separately in any of the populations. Therefore it is even more surprising that even without information about the distribution of idiopathic and secondary osteoarthritis the graphs show such strong parallelism. This may suggest that secondary osteoarthritis has more or less the same prevalence in different populations or that the prevalence of secondary osteoarthritis is low and does not influence the slope. Lack of information about risk factors and about the prevalence of secondary osteoarthritis limits causal inferences based on these comparison data. Surveys in areas where the prevalence of osteoarthritis is determined by the occurrence of special joint diseases like Mseleni joint disease ${ }^{30}$ and Kashin-Beck disease ${ }^{3132}$ were not included in this study.

Osteoarthritis is a slowly developing process, which makes it very difficult to approach the problem by intervention studies. We had hoped that comparison data of very different populations would give solutions for the many problems that surround the causes and development of this disease or group of diseases. The only data that could be compared from a reasonable number of surveys were the radiological data. Data on body mass index, pain, limitation of movement, bone mass, etc are not available from most of the populations. Further epidemiological studies of osteoarthritis, especially when prevention is one of the ultimate goals, should be directed towards differentiating the types of osteoarthritis. Secondary types, like crystal arthropathy, osteoarthritis developing in the course of endocrine disorders, and psoriasis, should be separated from so called idiopathic osteoarthritis. For a number of population surveys it is probably sufficient to re-evaluate the existing data and reread the radiographs.

We conclude that osteoarthritis is a worldwide disease and that no population investigated so far has been spared. Differences exist between populations. These differences are differences in level and whether they are real differences or due to interobserver variation or to differences in the distribution of risk factors or genetic differences has yet to be established. Joints. with a low prevalence of osteoarthritis in one population are relatively spared in all populations, while frequently affected joints show signs of degeneration in all populations. It is therefore most likely that the aetiology of most osteoarthritis is the same in all populations. Cartilage changes are the result of longstanding metabolic and mechanical processes. The relative importance 
of each of these processes can, unfortunately, not be compared because they are rarely available and even when available lack methodological standardisation. Similarities of slopes argue in favour of the possibility of extrapolating results from one population survey to others. Thus conclusions drawn about this Dutch population can be applied to other populations.

The authors wish to thank Dr H C M Haanen who was the second reader of most of the radiographs and Dr K Shichikawa who supplied the data from the Kamitonda study. This study was supported by grants from The Netherlands Prevention Fund and The Netherlands Foundation against Rheumatism.

\section{Note}

The following abbreviations are used in Tables 2 and 3: $C S-D D=$ cervical spine disc degeneration; $C S-F J=$ cercival spine facet joints; LS-DD=lumbar spine disc degeneration; $D I P=$ distal interphalangeal joints; $\mathbf{P I P}=$ proximal interphalangeal joints; $\mathrm{MCP}=$ metacarpophalangeal joints; $\mathrm{CMC}-\mathrm{I}=$ first carpometacarpal joints; $\quad \mathrm{CMC}-\mathrm{L}=$ =lateral carpometacarpal joints; $\quad \mathrm{TMT}=$ tarsometatarsal joints; MTP-I=first metatarsophalangeal joints MTP-L=lateral metatarsophalangeal joints; $\mathrm{SI}=$ sacroiliac joints

\section{References}

1 Acheson R. Heberden oration 1981. Epidemiology and the arthritides. Ann Rheum Dis 1982; 41: 325-34.

2 Kelsey J L. Prevalence studies of the epidemiology of osteoarthritis. In: Lawrence R C, Shulman L E, eds. Epidemiology of the rheumatic diseases. 1st ed. New York: Gower Medical, 1984: 282-8.

3 Lawrence J S, Bremner J M, Bier F. Osteoarthrosis. Prevalence in the population and relationship between symptoms and X-ray changes. Ann Rheum Dis 1966; 25: 1-24.

4 National Centre for Health Statistics. Prevalence of osteoarthritis by age, sex, race and geographic area. United States 1960-1962. Public Health Service Publication No 1000. 1966: series 11, No 15: 1-11.

5 Lawrence J S, Sebo M. The geography of osteoarthritis. In: Nuki G, ed. The aetiopathogenesis of osteoarthritis. 1st ed. London: Pitman Medical, 1980: 155-83.

6 Solomon L, Beighton P, Lawrence J S. Osteoarthrosis in a rural South African negro population. Ann Rheum Dis 1976; 35: 274-8.

7 Brighton S W, De La Harpe A L, Van Staden D A. The prevalence of osteoarthrosis in a rural African community. $\mathrm{Br} J$ Rheumatol 1985; 24: 321-5.

8 Valkenburg H A, Haanen H C M. The epidemiology of low back pain. In: White A A, Gordon S L, eds. Symposium on idiopathic low back pain. 1st ed. Miami, Florida: Mosby Company, 1982: 9-22.

9 Kellgren J H, Jeffrey M R, Ball J. Atlas of standard radiographs. Vol II. The epidemiology of chronic rheumatism. Oxford: Blackwell Scientific, 1963.

10 Haanen H C M. An epidemiological survey on low back pain. Rotterdam: Erasmus University, 1984: 50-2. (Thesis.)

11 Blumberg B S, Bloch K J, Black R L, Dotter C. A study of the prevalence of arthritis in Alaskan eskimos. Arthritis Rheum $1961 ; 4: 325-39$.
12 Bremner J M, Lawrence J S, Miall W E. Degenerative join $\bar{x}$ ? disease in a Jamaican rural population. Ann Rheum Dis 1968 27: 326-32.

13 Lawrence J S. Disc degeneration. Its frequency and relation to symptoms. Ann Rheum Dis 1969; 28: 121-38.

14 Bennet P H, Burch T A. Osteoarthrosis in the Blackfeet an Pima Indians. In: Kellgren J H, Jeffrey M R, Ball J, eds. Atlas of standard rediographs. Vol II. The epidemiology of chroni rheumatism. Oxford: Blackwell Scientific, 1963: 407-12.

15 Mikkelsen W M, Duff I F, Dodge H D. Age-specific prevalencể of radiographic abnormalities of the joints of the hands, wrist and cervical spine of adult residents of the Tecumseh, Michigan; community health study area, 1962-1965. J Chronic Dis 1970 23: 151-9.

16 Tzonchev V T, Pilossoff T, Kanev K. Prevalence of osteoarthria tis in Bulgaria. In: Bennett P H, Wood P H N, eds. Population studies of the rheumatic diseases. 1st ed. New York: Excerptä Medica, 1966: 413-6.

17 National Centre for Health Statistics. Basic data on arthritis knee, hip and sacroiliac joints in adults ages $25-74$ years. United States 1971-1975. Public Health Service Publication No 1000. 1979: series 11, No 213: 1-8.

18 Hartz A J, Fisher M E, Bril G, et al. The association of obesity with joint pain and osteoarthritis in the HANES data. J Chronic Dis 1986; 39: 311-9.

19 Byers P D, Contepomi C A, Farkas T A. A post mortem stud of the hip joint. Ann Rheum Dis 1970; 29: 15-31.

20 Lawrence R C, Everett D F, Cornoni-Huntley J, Hochbergo M C. Excess mortality and decreased survival in females witk osteoarthritis of the knee [Abstract]. Arthritis Rheum 1987; 30 S130.

21 Felson D T, Anderson J J, Naimark A, Walker A M, Meena R F. Obesity and knee osteoarthritis. The Framingham study Ann Intern Med 1988; 109: 18-24.

22 Saase J L C M van, Vandenbroucke J P, Romunde L K J vanФ् Valkenburg $\mathrm{H} \mathrm{A}$. Osteoarthritis and obesity in the generaf population. A relationship calling for an explanation. Rheumatol 1988; 15: 1152-8.

23 Lawrence J S. Hypertension in relation to musculoskeletał disorders. Ann Rheum Dis 1975; 34: 451-6.

24 Smythe H A. Osteoarthritis, insulin and bone density. Rheumatol 1987; 14: 91-3.

25 Dequeker J. The relationship between osteoporosis and osteoarthritis. Clin Rheum Dis 1985; 11: 271-96.

26 Solomon L. Bone density in ageing Caucasian and Africa色. populations. Lancet 1979; ii: 1326-9.

27 Horseman A. Bone mass. In: Nordin B E C, ed. Calcium phosphate and magnesium metabolism. 1st ed. Edinburgh? Churchill Livingstone, 1976: 357-404.

28 Radin E L. Paul I L, Rose R M. Role of mechanical factors ip pathogenesis of primary osteoarthrosis. Lancet 1972; i: 519-210

29 Altman R, Asch E, Bloch D, et al. Development of criteria for. the classification and reporting of osteoarthritis. Classification of osteoarthritis of the knee. Arthritis Rheum 1986; 29: 1039-49.

30 Yach D, Botha J L. Mseleni joint disease in 1981: decreasedn prevalence rates, wider geographical location than before, an\& socioeconomic impact of an endemic osteoarthrosis in afo underdeveloped community in South Africa. Int J Epidemi@ 1985; 14: 276-84.

31 Nesterov A I. The clinical course of Kashin-Beck disease Arthritis Rheum 1964; 7: 29-40.

32 Sokoloff L. Endemic forms of osteoarthritis. Clin Rheum D $\vec{s}$ 1985; 11: 187-202. 